\title{
O custo financeiro dos tributos sobre consumo nas cadeias de suprimento brasileiras: uma proposta metodológica
}

\author{
The financial cost of consumption taxes in brazilians supply chains: a methodological \\ proposal
}

\section{El costo financiero de los impuestos sobre el consumo en la cadena de suministro de Brasil: una propuesta metodológica}

\section{Daniel Fonseca Costa}

Doutorando em Administração pela Universidade Federal de Lavras

Professor do Instituto Federal de Minas Gerais - Campus Formiga

Endereço: Rua Padre Alberico, n॰ 440, Bairro São Luiz

CEP: 35.570-000 - Formiga/MG - Brasil

E-mail: daniel.costa@ifmg.edu.br

Telefone: +55 (37) 3322-8432

Caio Peixoto Chain

Doutorando em Administração pelo Universidade Federal de Lavras

Endereço: Av. Doutor Sylvio Menicucci, n॰ 1001, Bairro Kennedy

CEP: 37.200-000 - Lavras/MG - Brasil

E-mail: caiopeixotochain@gmail.com

Telefone: +55 (35) 3829-1453

\section{Francisval de Melo Carvalho}

Doutor em Administração pela Universidade Mackenzie

Professor do Programa de Pós-Graduação em Administração da Universidade Federal de Lavras

Endereço: Av. Doutor Sylvio Menicucci, n॰ 1001, Bairro Kennedy

CEP: 37.200-000 - Lavras/MG - Brasil

E-mail: francarv@dae.ufla.br

Telefone: +55 (35) 3829-1771

\section{Bruno César de Melo Moreira}

Doutor em Administração pela Universidade Federal de Santa Catarina

Professor do Instituto Federal de Minas Gerais - Campus Formiga

Endereço: Rua Padre Alberico, n॰ 440, Bairro São Luiz

CEP: 35.570-000 - Formiga/MG - Brasil

E-mail: bruno.melo@ifmg.edu.br

Telefone: +55 (37) 3322-8432

Artigo recebido em 04/05/2015. Revisado por pares em 19/05/2016. Reformulado em 19/06/2016. Recomendado para publicação em 10/07/2016 por Sandra Rolim Ensslin (Editora Científica). Publicado em 26/08/2016. 


\title{
Resumo
}

Entre as principais discussões fiscais no Brasil está o fato de os tributos indiretos onerarem sobremaneira os preços dos produtos e, consequentemente, influenciarem o padrão de consumo. Este trabalho teve o objetivo de propor um modelo para mensurar o custo financeiro dos tributos sobre consumo ao longo das cadeias de suprimentos e analisar a sensibilidade desse custo em relação ao tempo e ao valor agregado. Foram elaboradas equações com as incidências tributárias baseadas na legislação vigente, que foram aplicadas em uma cadeia de suprimentos simulada. Por fim, realizou-se uma análise de sensibilidade, por meio de regressão linear, em 200 cadeias hipotéticas. Essas análises corroboraram a tese de que quanto mais longa é a cadeia produtiva e quanto maior forem os valores agregados nos elos iniciais, maior será o custo financeiro. Pode-se concluir que o modelo é aplicável e que o custo financeiro dos tributos influencia o preço final de venda dos produtos.

Palavras-chave: Custo tributário. Custo financeiro. Tributos sobre o consumo. Cadeia de suprimentos.

\begin{abstract}
Among the main tax discussions in Brazil is the fact that indirect taxes greatly increases the product prices and consequently influence the consumption pattern. This work aimed to propose a model to measure the financial cost of excise taxes along one supply chain and analyze the sensitivity of this cost in relation to time and added value. Equations were developed with tax incidence, based on the current legislation and were applied in a simulated supply chain. Finally, was performed a sensitivity analysis by linear regression in 200 hypothetical supply chains. These analyzes confirmed the thesis that the longer the production chain and the greater are the added values in the initial links, the greater is the financial cost. It can be concluded that the model is applicable and that the financial cost of taxes influences the final selling price of the products.
\end{abstract}

Keywords: Tax cost. Financial cost. Consumption taxes. Supply chain.

\section{Resumen}

Entre las principales discusiones fiscales en Brasil es el hecho de que los impuestos indirectos gravan considerablemente los precios de productos y, por consiguiente influyen en el patrón de consumo. Este trabajo tuvo como objetivo proponer un modelo para medir el costo financiero de los impuestos sobre el consumo a lo largo de la cadena de suministro y analizar la sensibilidad de este costo en relación con el tiempo y el valor añadido. Se desarrollaron ecuaciones con incidencias fiscales, en base a la legislación vigente que y se aplicaron en una cadena de suministro simulada. Por último, se realizó un análisis de sensibilidad mediante regresión lineal en 200 cadenas hipotéticas. Estos análisis confirman la tesis de que cuanto mayor sea la cadena de producción y mayores son los valores agregados en los enlaces iniciales, mayor es el costo financiero. Se puede concluir que el modelo es aplicable y que el costo financiero de los impuestos influye en el precio de venta final de los productos.

Palabras clave: Costo fiscal. Costo financiero. Impuestos sobre el consumo. Cadena de suministros.

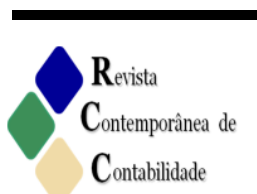




\section{Introdução}

Por diversas décadas, a alta carga tributária brasileira tem suscitado discussões no cenário produtivo nacional. Nesse sentido, a bandeira da reforma tributária tem sido levantada por políticos, acadêmicos e representantes de entidades empresariais e contábeis, no intuito de se buscar um sistema tributário mais justo e eficaz. Entretanto, observa-se que poucos esforços políticos concretos têm sido despendidos em prol da modernização da matriz tributária do Brasil.

O sistema tributário brasileiro é composto por tributos sobre o patrimônio, a renda, as operações financeiras e sobre o consumo. Essa matriz é definida pela Constituição Federal (CF) que atribui à União, aos Estados, ao Distrito Federal e aos Municípios a competência de instituir e cobrar os impostos (arts. 153 a 155). Além disso, o art. 149 da CF diz que a União pode instituir contribuições sociais e de intervenção no domínio econômico que também fazem parte do sistema tributário e contribuem para a arrecadação.

Toda essa diversidade de tributos tem proporcionado um aumento constante na arrecadação brasileira, principalmente aquela relacionada aos indiretos. Mesmo com esse aumento de arrecadação, a política tributária tem se mostrado inadequada, principalmente pelos inúmeros tributos, pela forma de se taxar o consumo, pela quantidade de alíquotas e pelo emaranhado de leis e de normas tributárias que tornam o sistema demasiadamente complexo.

Tal complexidade age em desfavor do contribuinte e do consumidor brasileiro que suporta um custo tributário elevado em contrapartida a um gasto público ineficaz. Gassen, D'Araújo e Paulino (2013) afirmam que a matriz tributária do Brasil é altamente regressiva e que as pessoas com menor capacidade contributiva são as que mais sofrem o esse ônus. Ademais, a composição da carga tributária do País concentra-se no consumo como principal base explorada, influenciando diretamente na formação dos preços dos produtos, impondo um viés fortemente regressivo que influencia as transações econômicas (FERNANDES; TEIXEIRA; BAPTISTA, 2010; PAES, 2012). Segundo Paes (2012, p.68), “a combinação de carga tributária elevada e grande concentração no consumo tornam o ambiente econômico particularmente difícil para as empresas".

Nesse sentido, a carga tributária do Brasil, em relação ao PIB, tem sido crescente durante os últimos anos, representando 34,61\% em 2012, 35,04\% em 2013 e 35,42\% em 2014 (INSTITUTO BRASILEIRO DE PLANEJAMENTO E TRIBUTAÇÃO, 2015). Além disso, os tributos sobre bens e consumo representaram, em 2014, 51,02\% do total da arrecadação tributária (RECEITA FEDERAL, 2015), demonstrando o alto peso dos tributos sobre o consumo na arrecadação brasileira.

Posto isto, verifica-se que os tributos indiretos oneram os preços dos produtos e, consequentemente, influenciam o padrão de consumo dos brasileiros que tendem a arcar com o ônus tributário ao final de uma cadeia de suprimento. Isso ocorre pelo fato de que os impostos sobre consumo, tais como o IPI (Imposto sobre Produtos Industrializados), o ICMS (Imposto sobre Operações relativas à Circulação de Mercadorias e sobre Prestações de Serviços de Transporte Interestadual e Intermunicipal e de Comunicação), o ISSQN (Imposto sobre Serviços de Quaisquer Natureza), o PIS (Programa de Integração Social) e a COFINS (Contribuição para o Financiamento da Seguridade Social) incidem ao longo da cadeia produtiva, onerando o produto em seu preço final pelo custo tributário. 
Dessa forma, a abordagem teórica institucional fornece embasamento para a investigação dos determinantes da sobrevivência das empresas, como a cultura organizacional, ambiente social e econômico, assim como a estrutura regulatória. Essa abordagem está interessada em como as organizações se posicionam em conformidade com as regras e normas sociais, como a relação com agências governamentais, leis, entre outras práticas sociais e culturais (GLOVER et al., 2014). Com isso, a questão tributária está inserida no ambiente regulatório em que as empresas estão presentes, dada a obrigatoriedade de se submeterem a esse ônus, bem como na influência que os tributos exercem na estratégia de formação do preço de venda do produto ao longo da cadeia de suprimentos.

No entanto, ainda que os impostos indiretos estejam ganhando cada vez mais importância em um ambiente econômico atual, sendo sua prática adotada em mais de 150 países (ERNEST \& YOUNG, 2012), não foram encontrados na literatura trabalhos que se ativessem a estudar o efeito financeiro dos tributos sobre o consumo ao longo da cadeia de suprimentos e no preço final dos produtos.

Sobre essa temática, os trabalhos científicos são desenvolvidos separadamente, pois avaliam apenas a perspectiva da cadeia de suprimentos ou, simplesmente, a estrutura tributária (WEBER, 2011). Em sua maioria, os trabalhos científicos com essa temática procuram discutir o custo tributário sobre os elos da cadeia produtiva e sobre o preço final do produto (ABRANTES; REIS; SILVA, 2009; MARION; MUEHLEGGER, 2011; REGAZZINI; BACHA, 2013), alíquotas e cargas tributárias mais eficientes (DEATON, 1981; TRABANDT; UHLIG, 2011) e sobre o impacto dos tributos indiretos na competitividade da cadeia produtiva (FREITAS; REVILLION; BELARMINO, 2015).

Além disso, a literatura econômica identificou que quanto maior é a defasagem temporal entre o fato gerador e o momento em que o tributo é efetivamente recolhido aos cofres públicos, menor será o valor real da arrecadação do governo. Esse fenômeno sobre as receitas governamentais é comum em períodos de aceleração inflacionária, como na economia brasileira nos anos 1980 e ficou conhecido como Efeito Tanzi (NETO, 1990). Seguindo uma lógica semelhante, o custo financeiro dos tributos também pode ter um efeito perverso sobre os consumidores, pois quanto maior a defasagem percorrida pelo produto ao longo da cadeia produtiva, maior será a participação desse custo no preço de venda do produto final.

Dessa forma, é latente a necessidade de se conhecerem os efeitos financeiros que os tributos indiretos causam nos elos das cadeias de suprimentos e nos preços dos produtos, o que justifica este estudo, que tem o objetivo de propor um modelo analítico para mensurar o custo financeiro dos tributos sobre consumo nas cadeias produtivas, bem como analisar a sensibilidade do custo financeiro dos tributos indiretos sobre um produto simulado, em relação aos fatores tempo e valor agregado, até o seu consumo final.

Para isso, propõe-se uma metodologia para mensurar esse custo ao longo da cadeia de suprimentos. O presente ensaio trata-se de um modelo teórico, com aplicações quantitativas, que defende a tese de que o custo financeiro dos tributos sobre o consumo está embutido no preço de venda ao longo da cadeia produtiva, bem como a de que esse custo aumenta quando existe maior agregação de valores nos elos iniciais e à medida que a cadeia se torna mais distante do consumidor.

Assim, o estudo se mostra relevante para a gestão tributária das empresas e das cadeias de suprimentos, pois apresenta uma metodologia de cálculo do custo financeiro provocado pelo custo tributário gerado pelos tributos indiretos que poderá ser utilizada e adaptada à realidade de cada empresa, de acordo com o ramo de atividade e porte, bem como à realidade

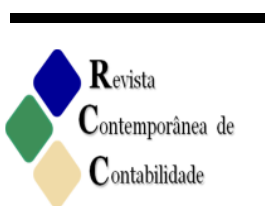

ISSN 2175-8069, UFSC, Florianópolis, v. 13, n. 29, p. 91-112, mai. /ago. 2016 
das diversas cadeias de suprimentos. Ademais, conhecer os impostos indiretos, incidentes no processo produtivo, se mostra relevante para todos os aspectos da cadeia de suprimentos, incluindo aspectos relacionados a planejamento, compras, logística e planejamento do melhor momento e local da venda do produto final (ERNEST \& YOUNG, 2012), bem como do melhor local para se estabelecer a base operacional da empresa (WEBER, 2011).

\section{Revisão Temática}

\subsection{Tributos sobre o Consumo}

Os tributos são classificados em diretos e indiretos. Os diretos são aqueles que possuem uma relação pessoal ou direta com o fato gerador. Os indiretos, por sua vez, são aqueles que incidem sobre a produção, sobre a circulação de mercadorias e sobre os serviços. Os indiretos também são classificados como tributos sobre o consumo, por serem repassados para o preço final dos produtos ou serviços (PEGAS, 2006).

No Brasil, os tributos indiretos são o IPI, o ICMS, o ISS (GASSEN; D'ARAÚJO; PAULINO. 2013), o PIS e a COFINS (FERNANDES; TEIXEIRA; BAPTISTA, 2010). Além desses, o IOF (Imposto sobre Operações Financeiras) também pode ser considerado como tributo sobre o consumo por onerar o consumidor final. Esses tributos são importantes para a arrecadação brasileira representando cerca de 68\% da arrecadação total (GASSEN; D'ARAÚJO; PAULINO. 2013). O IPI, o PIS e a COFINS são de competência da União, o ICMS dos Estados e do Distrito Federal e o ISS dos Municípios (arts. 149 e 153 a 155 da $\mathrm{CF})$.

Na visão de Gassen, D’Araújo e Paulino (2013), os tributos sobre consumo incidem nas diversas fases do processo produtivo, sendo a principal marca na matriz tributária brasileira. A alta concentração dos tributos indiretos na arrecadação e sua distribuição desproporcional na cadeia produtiva faz com que as indústrias brasileiras tenham um dos níveis mais elevados de tributação do mundo, fazendo com que a tributação brasileira sobre o consumo seja ineficiente, principalmente pela quantidade de tributos e alíquotas (PAES, 2012).

Além disso, essa incidência de tributos sobre o consumo, ao longo da cadeia de suprimentos, faz com que os consumidores não tenham a noção exata da real carga tributária embutida no preço final dos produtos (GASSEN; D'ARAÚJO; PAULINO. 2013). Essa afirmativa foi corroborada por Regazzini e Bacha (2013), que verificaram que a carga tributária não é facilmente observada em função da complexidade do sistema tributário brasileiro. Assim, o sistema de tributação indireta, além de impactar diretamente nos produtos finais, influencia os produtos intermediários, interferindo nas transações ao longo das cadeias de suprimentos, fato este que onera o processo produtivo e, por consequência, os preços dos produtos para o consumidor (FERNANDES; TEIXEIRA; BAPTISTA, 2010).

Com essas características, o atual sistema tributário faz com que pessoas com menor capacidade contributiva arquem com a maior parte dos tributos arrecadados. Esse peso do tributo sobre as pessoas menos favorecidas faz com que o sistema tributário brasileiro seja regressivo (GASSEN; D'ARAÚJO; PAULINO. 2013). O sistema tributário regressivo, na visão de Marquezini (2005), é aquele que pesa mais sobre as pessoas com menor poder aquisitivo e, de forma contrária, um sistema progressivo ocorre quando a sociedade impõe um maior peso tributário aos que possuem maior renda. Nesse sentido, Silva e Payeras (2013) 
estimaram a carga tributária indireta em relação à renda da população da região Sul do Brasil e verificaram que a carga tributária indireta sobre alimentos é regressiva quando se consideram a renda e as despesas das famílias.

Além disso, o modelo de incidência múltipla sobre a mesma base de cálculo faz com que haja aumento dos demais tributos relacionados (FERNANDES; TEIXEIRA; BAPTISTA, 2010). Para Marquezini (2005), apesar de os tributos sobre o consumo obedecerem ao princípio da não cumulatividade, a complexidade do sistema arrecadatório e a diversidade de alíquotas e regras provocam a guerra fiscal, o planejamento tributário excessivo e a sonegação.

Nesse sentido, Paes (2012) propõe a simplificação da tributação sobre o consumo e a utilização de uma alíquota única, com o argumento de que isso reduz a perda de eficiência econômica, além de facilitar a identificação do quanto de tributos está embutido no preço dos produtos. $\mathrm{O}$ autor ainda complementa argumentando que a simples remoção das distorções tributárias é capaz de melhorar indicadores econômicos. Para Gassen, D'Araújo e Paulino (2013), essa simplificação traria mais transparência tributária. Assim, os autores sugerem um único imposto sobre o valor agregado, o que resultaria numa redução de alíquota e, consequentemente, na redução do preço final dos produtos.

Nessa linha, Keen e Lockwood (2010) elaboraram um estudo empírico com dados em painel que observou 143 países ao longo de 25 anos, incluindo o Brasil, para caracterizar a decisão de adotar o Imposto sobre Valor Agregado (IVA) e, depois de implantado, seu impacto na receita tributária nacional. As estimativas encontradas pelos autores apontaram evidências de que o IVA pôde ser considerado um instrumento de tributação eficiente na maioria dos países que adotou esse formato de política fiscal, com resultados controversos apenas para determinados países da África.

Assim, tributos sobre consumo, como o Imposto sobre Valor Agregado, podem ser considerados o principal instrumento de aumento de arrecadação para financiar o desenvolvimento humano e econômico local, como explanado por CNOSSEN (2015). Essa estratégia vem sendo utilizada por diversos países da África, visto que essa tributação é menos prejudicial ao crescimento econômico em comparação com a tributação sobre a renda. Ainda segundo o autor, um aumento na base de incidência do VAT não somente eleva receitas, mas também reduz distorções econômicas e a complexidade da gestão tributária em relação aos demais tipos de tributação.

\subsection{Tributação nas Cadeias de Suprimentos}

O termo "cadeia de suprimentos", segundo Mentzer et al. (2001), foi definido como um conjunto de três ou mais organizações (ou indivíduos) diretamente envolvidas nos fluxos a montante e a jusante de produtos, serviços e/ou informações da fonte até o consumidor. Ainda segundo os autores, a gestão dessa cadeia (Supply Chain Management) pode ser descrita como a coordenação estratégica e sistêmica das funções empresariais tácitas e tradicionais da empresa individual e entre empresas em uma cadeia de suprimentos, com o propósito de incrementar o desempenho de longo prazo da firma específica e da cadeia em conjunto.

Uma densa e sistematizada revisão teórica a respeito da cadeia de suprimentos pode ser encontrada em Burgess, Singh e Koroglu (2006), Fabbe-Costes e Jahre (2008) e Arzu Akyuz e Erman Erkan (2010). Dado o objetivo do presente trabalho, foi feito um referencial específico acerca da relação entre cadeias produtivas e de suprimentos com a tributação, visto 
que a literatura recente a respeito das cadeias de suprimentos dispende pouca atenção às questões fiscais (BALAJI; VISWANADHAM, 2008; WEBBER, 2011).

O efeito da tributação nos elos da cadeia de combustíveis até sua chegada ao preço final do varejo nos Estados Unidos foi estudado por Marion e Muehlegger (2011). Considerando uma cadeia de suprimentos composta de quatro estágios - refino, transporte a granel, armazenamento e entrega ao varejo -, os autores confirmaram que existe um repasse total e até mais do que proporcional dos impostos federais e estaduais incidentes tanto na gasolina como no diesel para o preço final pago pelo consumidor. Esses resultados corroboraram as evidências encontradas por Alm, Sennoga e Skidmore (2009) em especial para o mercado de gasolina, considerados mais competitivos.

Ao estudar o montante de tributos que compõe o preço final do café em Minas Gerais, Abrantes, Reis e Silva (2009) observaram que, apesar da baixa incidência de impostos no segmento da produção rural provocada por diferimentos, redução de base de cálculo e isenção, o efeito ao longo da cadeia é representativo, principalmente devido à cumulatividade causada pela multiplicidade de incidências dos diversos tributos e encargos sociais.

A arrecadação tributária estadual de ICMS do Mato Grosso foi utilizada por Dallemole, Falleiros e Faria (2013) como variável para mensurar os municípios especializados na cadeia produtiva do algodão. Na visão dos autores, o ICMS foi considerado o principal insumo de programas de estímulo fiscal, em que sua desoneração e consequente aumento de competitividade das firmas atuou como fator de aglomeração para atividade econômica da cotonicultura na região.

Os resultados do trabalho de Regazzini e Bacha (2013) demonstraram que os segmentos do processo produtivo que mais contribuíram para a carga tributária total do setor sucroenergético em São Paulo foram aqueles que adicionaram mais valor ao produto, ou seja, a indústria. Além disso, demonstram que a indústria, por ser a fase da cadeia produtiva que possui menor número de empresas, é a que está mais exposta à incidência tributária, principalmente pelos artifícios legais de antecipação tributária, tal como a substituição tributária. Por fim, concluem que o varejo contribui pouco no montante da carga tributária.

Em relação à elaboração de referenciais analíticos sobre tributação em cadeias produtivas, devem ser destacadas as contribuições de Feng e Wu (2009). Esses autores desenvolveram um modelo teórico para estimar a redução das despesas tributárias com a finalidade de maximizar o lucro depois das deduções fiscais com base na opção locacional e no processo produtivo adotado por empresas inseridas em cadeias globais. Os fatores tributários considerados na pesquisa foram: imposto de importação, tributo por valor adicionado e imposto sobre pessoa jurídica.

O mercado de diesel norte-americano passou por transformações nas últimas décadas em que a tributação passou do elo varejista para fornecedores primários a maioria dos estados. Em uma investigação sobre sonegação nessa cadeia produtiva, Kopczuk et al. (2016) verificaram que preços do diesel no varejo são maiores e que os tributos incidentes sobre esse produto são repassados ao preço no varejo em maior magnitude nos estados em que a coleta está no fornecedor primário, sugerindo que esse novo regime de coleta reduziu a sonegação.

Com o objetivo de propor um método de preços baseado no custo de curto prazo da rede de cadeia de suprimento, levando em consideração o imposto sobre o valor acrescentado e o Imposto de Renda, Zhang e Huang (2014) propuseram um modelo matemático que pode ser aplicado na gestão e no controle de custo de um empreendimento ou de uma empresa. Os autores verificaram que a função do custo médio de cada unidade de produção diminui com o aumento da produção. 
Outro ponto importante é o que foi abordado pela pesquisa de Dyreng et al. (2015), que demonstrou que empresas norte-americanas têm utilizados holdings estrangeiras, em suas cadeias de suprimentos, localizadas em países que tributam menos a distribuição de capital. Além disso, os autores verificaram que as empresas americanas têm mais propensão de abrir suas holdings em países com menos corrupção e com menos risco de investimento, tais como os Países Baixos.

\section{Proposta Metodológica}

A presente proposta irá estabelecer um determinado momento temporal como início da cadeia. Esse pressuposto foi adotado por se considerar que o início de uma cadeia produtiva e de suprimento tende ao infinito, uma vez que sempre é necessário produzir insumo para a produção de outros insumos que serão utilizados no processo de extração, produção ou industrialização, além de que a indústria, o atacado ou o varejo podem fornecer insumos para a extração, produção ou industrialização por meio de um movimento circular.

Nesse sentido, com o intuito de estabelecer uma proposta metodológica generalista, equacionam-se os preceitos legais, sem entrar no mérito das especificidades tributárias, do ICMS, do PIS e da COFINS e do IPI, com a finalidade de apurar o quanto de tributo incide sobre o valor da receita bruta e, consequentemente, sobre o preço dos produtos em cada elo da cadeia de suprimento. Após esse feito e na busca de atender ao objetivo precípuo do presente estudo, propõe-se uma equação que irá mensurar o custo financeiro dos tributos sobre o consumo incorrido em um determinado produto na cadeia de suprimento.

Para isso, adota-se, para essa proposta, como custo tributário, aquele advindo dos próprios tributos em cada elo da cadeia de suprimentos (ABRANTES; REIS; SILVA, 2009) e como custo financeiro, aquele obtido a partir do custo tributário em função do tempo e de uma taxa de oportunidade (ROSS et al., 2015; ASSAF NETO, 2013).

O ICMS é de competência dos Estados e do Distrito Federal e está previsto pelo art. 155 da Constituição Federal e instituído pela Lei Complementar n. 87/1996. Esse imposto incide sobre a circulação de mercadorias e sobre prestações de serviços de transporte interestadual e intermunicipal e de comunicação. O inciso I do §2 da Constituição Federal diz que o ICMS é um imposto não cumulativo, isso significa que o valor devido de ICMS em cada operação relativa à circulação de mercadorias ou prestação de serviços será compensado com o montante de ICMS pago nas operações anteriores.

Em relação à cadeia de suprimento e perante às premissas legais para apuração do ICMS, entende-se que esse imposto incidirá em cada parte da cadeia, pela aplicação de uma alíquota, sendo permitido o aproveitamento do ICMS pago nas fases anteriores. Diante disso, a presente proposta analítica estabelece um momento inicial para a cadeia de suprimento, ressaltando que esse modelo é geral, e cada cadeia específica terá seu início estabelecido de acordo com sua dinâmica.

No início da cadeia irá se apurar o ICMS aplicando a alíquota sobre o preço de venda dessa fase, conforme a Equação 1:

$$
I c m s_{1}=P v_{1} \times A l_{1}
$$

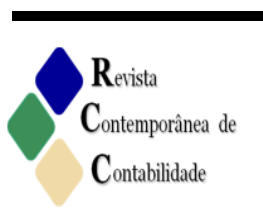

ISSN 2175-8069, UFSC, Florianópolis, v. 13, n. 29, p. 91-112, mai. /ago. 2016 
Em que: $P v_{l}=$ Preço de Venda da primeira fase da cadeia de suprimento, e $A l_{l}=$ Alíquota da primeira fase da cadeia de suprimento.

$\mathrm{Na}$ presente proposta analítica, a alíquota pode ser aplicada sobre o preço de venda, conforme a Equação 1, ou o preço de venda pode ser substituído pela receita bruta do produto, quando o modelo analítico for utilizado para análise do custo financeiro da cadeia como um todo e não necessariamente sobre um único produto. Nesse caso, substitui-se a $P v_{l}$ pelo $R b_{1}$ (Receita Bruta) em todas as equações da proposta.

Na segunda fase da cadeia de suprimentos, o ICMS será apurado mediante a aplicação da alíquota sobre o preço de venda, deduzindo-se, portanto, o ICMS da fase 1 da cadeia, conforme a Equação 2:

$$
I C m s_{2}=\left(P v_{2} \times A l_{2}\right)-I c m s_{1}
$$

$\mathrm{Na}$ terceira fase, o ICMS será apurado, aplicando-se a alíquota estabelecida sobre o preço de venda e deduzindo os ICMS pagos na primeira e na segunda fase, conforme a Equação 3:

$$
I c m s_{3}=\left(P v_{3} \times A l_{3}\right)-\left(I c m s_{1}+I c m s_{2}\right)
$$

As demais fases da cadeia de suprimentos seguem a mesma lógica das anteriores, ou seja, a cada etapa aplica-se a alíquota sobre o preço de venda, diminuindo o total de ICMS pago nas etapas anteriores. Diante disso, a Equação 4 demonstra o ICMS em uma cadeia com $n$ etapas:

$$
I c m s_{n}=\left(P v_{n} \times A l_{n}\right)-\left(I c m s_{1}+I C m s_{2}+I C m s_{3}+\cdots+I C m s_{n-1}\right)
$$

Em que: $n=$ e-nésima etapa da cadeia de suprimentos.

O total do ICMS incorrido na cadeia de suprimentos pode ser obtido pelo somatório do ICMS apurado em cada etapa da cadeia, conforme a Equação 5. Esse valor está embutido no preço final dos produtos que fazem parte da cadeia produtiva.

$$
I c m s_{t}=I c m s_{1}+I C m s_{2}+I C m s_{3}+\cdots+I c m s_{n}
$$

Além do ICMS apurado de forma convencional, a legislação prevê a cobrança desse imposto por substituição tributária. No regime de substituição tributária, as empresas produtivas, o importador ou aquele que primeiro receber o produto no Estado de destino se tornam substitutos no recolhimento do ICMS, ou seja, configuram-se como os responsáveis perante a legislação para recolher o imposto no lugar do contribuinte. Essa situação faz com que o ICMS seja recolhido nas fases iniciais da cadeia de suprimentos.

A forma mais comum de cálculo do ICMS por substituição tributária é pela aplicação de uma MVA (Margem de Valor Agregado) sobre "o preço praticado pelo remetente, acrescido dos valores correspondentes a descontos concedidos, inclusive o incondicional, frete, seguro, impostos, contribuições, royalties relativos à franquia e de outros encargos transferíveis ou cobrados do destinatário" (Item 3 da alínea a do inciso I do art. 19 do Anexo XV do RICMS/MG), para encontrar a base de cálculo do ICMS ST, sobre essa base aplica-se 
a alíquota de ICMS e, por fim, subtrai-se o ICMS pago na operação normal. A Equação 6 representa o ICMS da primeira fase da cadeia, quando esse é tributado por substituição tributária.

$$
\text { IcmsSt } t_{1}=\left(P v_{1} \times M v a_{1}\right) \times A l_{1}
$$

Em que: $M v a_{1}=$ Margem de Valor Agregada.

No caso em que a substituição tributária do produto ocorre na segunda fase da cadeia de suprimentos, além da aplicação da alíquota sobre o preço de venda acrescido da MVA, deduz-se o ICMS da Fase 1. O ICMS da Fase 1 é obtido pela equação 1.

$$
I c m s S t_{2}=\left(\left(P v_{2} \times M v a_{2}\right) \times A l_{2}\right)-I c m s_{1}
$$

Se a substituição tributária ocorrer nas fases subsequentes da cadeia produtiva, utilizase a Equação 8, que é composta pela Equação 6, deduzida dos ICMS normais apurados nas operações anteriores, conforme Equações 1, 2, 3 e 4.

$$
\text { IcmsSt }_{n}=\left(\left(P v_{n} \times M v a_{n}\right) \times A l_{n}\right)-\left(I c m s_{1}+I c m s_{2}+\cdots+I c m s_{n-1}\right)
$$

Em relação à Equação 8, há de se ressaltar que, se em alguma etapa de industrialização de produtos, se o ICMS tiver tributação normal de ICMS, porém sua matéria-prima for submetida ao recolhimento por substituição tributária, a fase industrial pode aproveitar, como crédito, o ICMS normal e o recolhido por substituição tributária nas fases anteriores.

O ICMS total da cadeia de suprimentos pode ser obtido pela soma dos ICMS recolhidos em cada etapa, finalizando com o ICMS recolhido por substituição tributária, conforme a Equação 9. Há de se ressaltar que, nas etapas de industrialização de produtos que possuem tributação normal de ICMS, a indústria pode aproveitar o crédito do ICMS normal das matérias-primas, bem como o ICMS recolhido por substituição tributária quando for o caso.

$$
I c m s S t_{t}=I c m s_{1}+I c m s_{2}+\cdots+I c m s_{n-1}+I c m s S t_{n}
$$

Por sua vez, o PIS e a COFINS são contribuições pertencentes à União, previstas pelo art. 195 da Constituição Federal. O PIS e a COFINS são cobrados pela modalidade cumulativa e não cumulativa, sendo que a primeira incide sobre o faturamento sem direito a créditos, e a segunda também incide sobre o faturamento, porém com o direito ao aproveitamento de créditos das contribuições pagas nas operações anteriores. A presente proposta adota a modalidade não cumulativa, sendo passível de adaptação quando da aplicação do modelo em cadeias onde a modalidade cumulativa destaca-se em algumas fases. Diante disso, o PIS e a COFINS, na fase inicial da cadeia de suprimentos, são calculados sobre o preço de venda mediante a aplicação do somatório das alíquotas das duas contribuições, conforme a Equação 10:

$$
\text { PisCof } f_{1}=P v_{1} \times A l_{1}
$$


A partir da segunda fase, as contribuições podem ser obtidas aplicando-se as alíquotas sobre o preço de venda e deduzindo-se o que foi recolhido na primeira fase, conforme a Equação 11:

$$
\operatorname{PisCof} f_{2}=\left(P v_{2} \times A l_{2}\right)-P i s \operatorname{Cof}_{1}
$$

As demais fases seguem a mesma lógica, por exemplo, na fase três, apura-se o PIS e a COFINS por meio da aplicação das alíquotas e deduz-se o PIS e a COFINS recolhidos nas fases um e dois, conforme a Equação 12:

$$
\text { PisCof }=\left(P v_{3} \times \mathrm{Al}_{3}\right)-\left(\operatorname{PisCof}_{1}+\operatorname{PisCof}_{2}\right)
$$

Em resumo, o PIS e a COFINS, incidentes na cadeia de suprimentos, seguem a lógica da Equação 13, ou seja, a cada fase aplicam-se as alíquotas sobre o preço de venda e diminuise o que foi recolhido nas fases anteriores:

$$
\operatorname{PisCof}_{n}=\left(\operatorname{Pv}_{n} \times A l_{n}\right)-\left(\operatorname{PisCof}_{1}+\operatorname{PisCof}_{2}+\operatorname{PisCof}_{3}+\cdots+\operatorname{Piscof}_{n-1}\right.
$$

O total do PIS e da COFINS, em toda cadeia produtiva, pode ser obtido pelo somatório do que foi recolhido em todas as fases, conforme a Equação 14. Como ocorre no ICMS, o PIS e a COFINS são embutidos nos preços de vendas dos produtos em todas as fases:

$$
\text { PisCof }_{t}=\text { PisCof }_{1}+\text { PisCof }_{2}+\text { PisCof }_{3}+\cdots+\text { PisCof }_{n}
$$

O IPI também é um imposto de competência da União e está previsto no art. 153 da Constituição Federal. O IPI é estratégico para a União, uma vez que incide sobre os produtos industrializados, e sua alíquota pode ser alterada pelo poder executivo ( $\left(1^{\circ}\right.$ do art. $\left.153 \mathrm{da} C F\right)$. O IPI incide apenas sobre a fase industrial, não havendo previsão para a fase comercial. O cálculo do IPI difere do cálculo do ICMS, PIS e COFINS, por ser por fora, ou seja, calcula-se o imposto sobre o valor dos produtos e o adiciona no valor total da Nota Fiscal. No caso dos demais tributos, que são por dentro, a base de cálculo e o valor total da Nota Fiscal são iguais. Isso faz com que esses tributos incidam sobre eles mesmos. Além disso, o IPI também responde ao princípio da não cumulatividade (Inciso II do $\S 3^{\circ}$ do art. 153 da CF).

A proposta do IPI é similar à do ICMS, à do PIS e à da COFINS. Primeiramente, o modelo estabelece um início para a cadeia de suprimento. Nesse sentido, o IPI será apurado mediante a aplicação da alíquota, quando for o caso, sobre uma base de cálculo que é formada pela receita bruta deduzida do próprio IPI, conforme a Equação 15:

$$
I p i_{1}=\frac{P v_{1}}{\left(1+A l_{1}\right)} \times A l_{1}
$$

No caso em que a cadeia tenha mais de uma fase industrial, a partir da segunda aplicase a alíquota sobre a base de cálculo e desconta-se o IPI pago nas fases anteriores, ou seja, na Fase 2 apura-se o IPI e deduz-se o IPI pago na Fase 1, conforme a Equação 16: 


$$
I p i_{2}=\left(\frac{P v_{2}}{\left(1+A l_{2}\right)} \times A l_{2}\right)-I p i_{1}
$$

Em suma, o processo de apuração do IPI segue a mesma lógica em todas as fases industriais, ou seja, apura-se o IPI aplicando-se a alíquota sobre a base de cálculo, deduzindose os valores pagos nas operações anteriores, conforme a Equação 17:

$$
I p i_{n}=\left(\frac{P v_{n}}{\left(1+A l_{n}\right)} \times A l_{n}\right)-\left(I p i_{1}+I p i_{2}+\cdots+I p i_{n}\right)
$$

O total de IPI pago no decorrer da cadeia produtiva pode ser dado pelo somatório dos valores pagos em cada fase da cadeia, conforme a Equação 18. Conforme exposto, o IPI incide sobre a fase industrial e seu valor é repassado para o preço final dos produtos.

$$
I p i_{t}=I p i_{1}+I p i_{2}+\cdots+I p i_{n}
$$

Dessa forma, o somatório de todos os tributos sobre o consumo, ICMS, PIS, COFINS e IPI, em cada elo da cadeia de suprimento, representa o custo tributário que foi embutido no preço de venda daquela operação. Sendo assim, a Equação 19 demonstra a apuração desse valor por operação:

$$
\text { CustoTrib }_{n}=\text { Icms }_{n}+\text { PisCof }_{n}+\operatorname{Ipi}_{n}
$$

A partir da compreensão da incidência do ICMS, do PIS, da COFINS e do IPI sobre a cadeia de suprimentos, busca-se mensurar o custo financeiro desses desembolsos ao longo do tempo. Como justificado, alguns trabalhos buscam mensurar o quanto de tributo incide sobre o preço de determinados produtos, portanto é necessário demonstrar o efeito financeiro dos tributos ao longo da cadeia.

Partindo do objetivo central deste trabalho, propõe-se uma capitalização composta (ASSAF NETO, 2012) dos valores pagos ao longo da cadeia de suprimento, a uma taxa que remunera o custo de oportunidade, para mensurar o custo financeiro dos tributos, que, por sua vez, onera o preço de venda dos produtos. A proposta é genérica, podendo ser adaptável a qualquer cadeia de suprimento, podendo também ser utilizada por empresas para mensurar o custo financeiro embutido nos preços finais de seus produtos.

Diante disso, o custo financeiro é obtido por meio do somatório dos tributos sobre o consumo em cada fase da cadeia de suprimento, capitalizado a uma taxa que remunera o custo de oportunidade $(i)$ ao longo do tempo. Como taxa, sugere-se a utilização do custo de capital (ROSS et al., 2015), quando for possível; caso contrário, utilizar taxas de financiamento praticadas pelo mercado. O tempo e a taxa podem variar de acordo com a fase da cadeia. Assim, o custo financeiro pode ser obtido pela Equação 20:

$$
\begin{aligned}
& \text { CustoFin }=\left\{\left[\text { Icms }_{1}+\text { PisCof }_{1}+\operatorname{Ipi}_{1}\right] \times\left[(1+i)^{n}-1\right]\right\}+\left\{\left[\text { Icms }_{2}+\text { PisCof }_{2}+\right.\right. \\
& \text { Ipi } \left.\left.i_{2}\right] \times\left[(1+i)^{n-n_{1}}-1\right]\right\}+\cdots+\left\{\left[\text { Icms }_{n}+\text { PisCof }_{n}+I p i_{n}\right] \times\left[(1+i)^{n-n_{n}}-1\right]\right\}
\end{aligned}
$$

O tempo $(n)$ será obtido em dias, em meses ou por meio de outra medida temporal que se alinhe à cadeia ou ao produto que será estudado. Para a medida de tempo em cada 
transação da cadeia de suprimento, leva-se em consideração o fato gerador (venda) do tributo como ponto inicial do período, bem como os tempos decorrentes de produção, de estocagem e de trânsito, até que o produto seja fruto de nova venda ou chegue ao consumidor final. Em resumo, o tempo de cada elo é contado a partir da venda do insumo ou do produto até que o insumo, o produto ou um novo produto sejam novamente vendidos.

O percentual do custo financeiro sobre a receita bruta ou sobre o preço de venda pode ser obtido pela Equação 21:

$$
\text { CustoFin }{ }_{\%}=\frac{\text { CustoFin }}{R b} \times 100,
$$

Em que: a $R b$ representa a Receita Bruta da última fase da cadeia de suprimento ou o preço final para o consumidor final $(P v)$.

Assim, o custo tributário total é representado pela soma do custo tributário e do custo financeiro, obtidos respectivamente pelas Equações 19 e 20.

Tal proposta metodológica, além de ser aplicada nos produtos específicos, pode ser aplicada nas cadeias de suprimento com o objetivo de analisar o custo tributário e o custo financeiro que estão embutidos no preço de venda dos diversos elos da cadeia, até chegar ao consumidor final. Sendo assim, a Figura 1 demonstra o modelo teórico desenvolvido.

Figura 1 - Demonstração da proposta de mensuração dos custos financeiros em uma cadeia de suprimentos

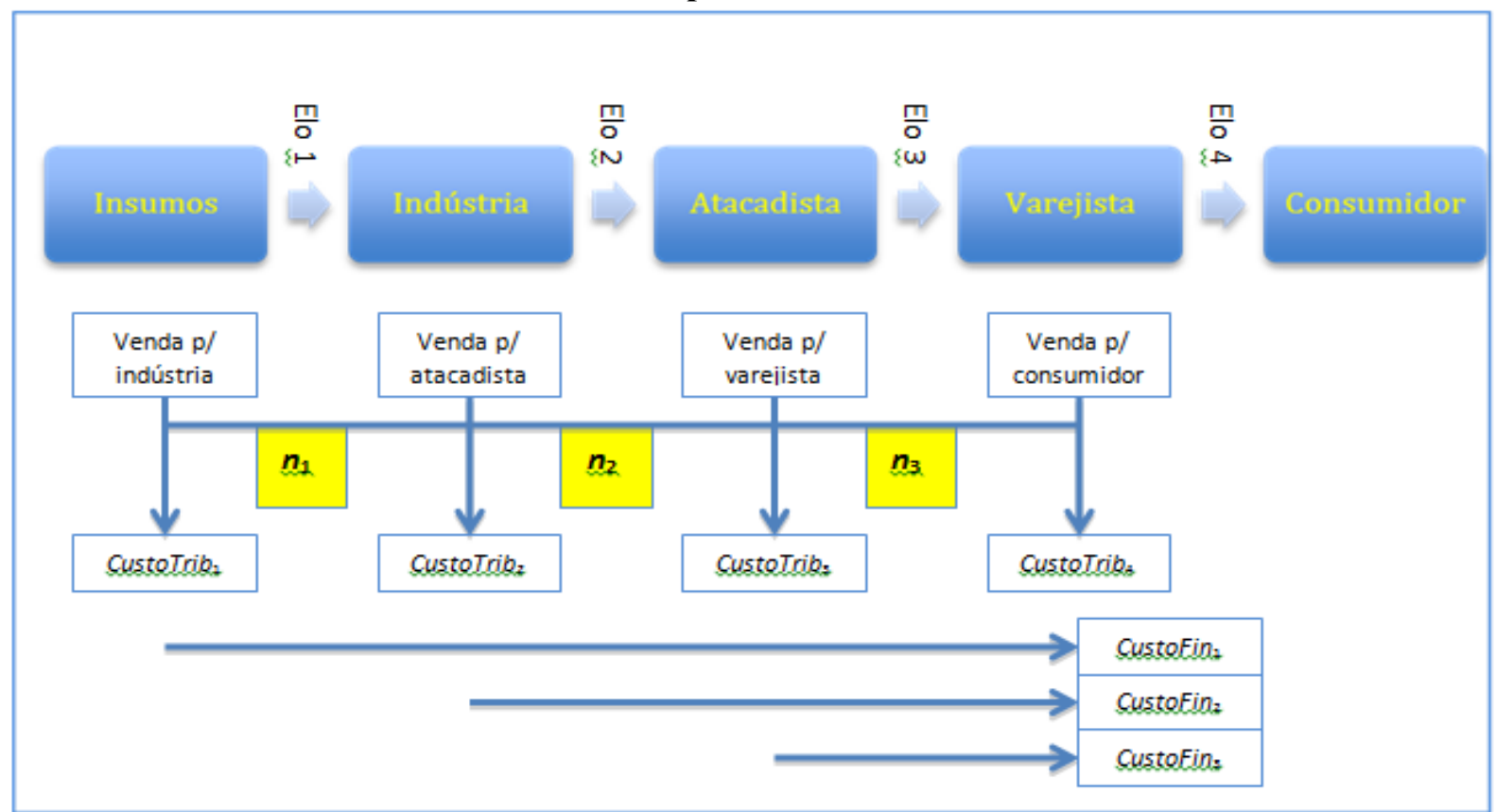

Fonte: Elaborado pelos autores.

A Figura 1 demonstra que, a cada operação de venda realizada em cada um dos elos da cadeia de suprimentos, faz nascer o fato gerador para os tributos destacados na proposta analítica (ICMS, PIS, COFINS e IPI). A partir desses fatos geradores, têm-se os custos tributários de cada elo, que, ao serem somados, representarão o custo tributário embutido no preço dos produtos. Além disso, o tempo $n$ representa o intervalo em que o produto é vendido por um participante da cadeia, até o momento que o produto industrializado ou o mesmo 
produto é vendido por outro membro da cadeia. O somatório do tempo de cada cadeia representa o tempo total que o produto leva para chegar às mãos do consumidor final.

Dessa forma, a soma do custo tributário de cada elo produz o custo tributário do produto e a associação do custo tributário de cada etapa com o tempo necessário para que o produto chegue ao consumidor final faz surgir o custo financeiro, que pode ser obtido pela Equação 20. O somatório do custo tributário (Equação 19) de cada operação e do custo financeiro (Equação 20), produzido pelo efeito temporal e por uma taxa de oportunidade, representa o custo tributário total, que está embutido no preço final do produto.

\section{Resultados e Discussão}

\subsection{Demonstração do Modelo}

A aplicação da proposta analítica para mensurar o efeito financeiro das cadeias produtivas de suprimentos foi realizada por meio de simulação, dado o caráter generalista do modelo. Supõe-se uma cadeia formada por quatro elos e composta pelo fornecedor de insumos (primeiro sujeito da cadeia), pela indústria, pelo comércio atacadista, pelo comércio varejista e pelo consumidor, conforme Figura 1.

Para ilustração e aplicação da proposta analítica, toma-se como base valores hipotéticos que posteriormente foram utilizados para balizar a simulação dos diversos cenários de distintas cadeias de suprimentos utilizadas na análise de sensibilidade (Tópico 4.2).

a) Valor do preço de venda do fornecedor de insumos $=\mathrm{R} \$ 400,00$.

b) Tempo entre a venda dos insumos e a venda do produto industrializado $=4$ meses.

c) Valor do preço de venda da indústria $=\mathrm{R} \$ 600,00$.

d) Tempo entre a venda do produto industrializado pela indústria e a venda do mesmo produto pelo atacadista $=4$ meses.

e) Valor do preço de venda praticado pelo comércio atacadista $=\mathrm{R} \$ 800,00$.

f) Tempo gasto entre a venda do produto pelo atacadista e a venda do mesmo produto pelo varejista $=4$ meses.

g) Valor do preço de venda praticado pelo varejista $=R \$ 1.000$.

h) Taxa de juros $=2 \%$ ao mês.

i) Alíquota de ICMS em todos os elos $=18 \%$.

j) Alíquota de PIS e COFINS em todos os elos $=9,25 \%(1,65 \%+7,6 \%)$.

k) Alíquota de IPI utilizada nas Fases 1 e 2 da cadeia de suprimento $=5 \%$.

Com base nas informações apresentadas, na primeira fase da cadeia de suprimento, os insumos foram vendidos por R $\$ 400,00$. Com isso, calcula-se o ICMS, o PIS e a COFINS e o IPI do primeiro elo da cadeia de suprimento com base nas Equações 1, 10 e 15.

Icms $_{1}=400 \times 0,18=72,00$

PisCof $_{1}=400 \times 0,0925=37,00$ 
$I p i_{1}=\frac{400}{(1+0,05)} \times 0,05=19,05$

O custo tributário do primeiro elo da cadeia é representado pelo somatório dos valores do ICMS, do PIS e da COFINS e do IPI (Equação 19). No exemplo, o custo foi de R\$ 128,05. Esse valor encontra-se incluído no preço de venda e representa, no caso do exemplo, 32,01\%.

$\mathrm{Na}$ segunda fase da cadeia produtiva, o produto foi vendido pela indústria por $\mathrm{R} \$$ 800,00. Sendo assim, o custo tributário pode ser obtido por meio das Equações 2, 11 e 16, conforme demonstrado abaixo:

$$
\begin{aligned}
& \text { Icms }_{2}=(600 \times 0,18)-72,00=36,00 \\
& \text { PisCof } f_{2}=(600 \times 0,0925)-37,00=18,50 \\
& I p i_{2}=\left(\frac{600}{1+0,05} \times 0,05\right)-19,05=9,52
\end{aligned}
$$

O custo total dos tributos indiretos, no segundo elo da cadeia produtiva, foi de R\$ 64,02. Ao somar o custo tributário do primeiro elo com o custo da segunda fase chega-se a um valor de R $\$ 192,07$, que representa 32,01\% do preço de venda de $\mathrm{R} \$ 600,00$.

$\mathrm{Na}$ terceira etapa da cadeia de suprimentos, o preço de venda praticado pelo atacadista foi de R $\$ 800,00$. Para se obter o custo tributário, foram utilizadas as Equações 3 e 12. Nessa fase, não há a incidência do IPI por não se tratar de industrialização.

$$
\begin{aligned}
& \text { Icms }_{3}=(800 \times 0,18)-(72,00+36,00)=36,00 \\
& \text { PisCof } \\
& 3 \text { is }=(800 \times 0,0925)-(37,00+18,50)=18,50
\end{aligned}
$$

Conforme demonstrado pelas equações, o custo tributário desse elo foi de $\mathrm{R} \$ 54,50$. Ao somar com o custo das demais fases, chega-se a um montante de $\mathrm{R} \$ 246,57$, que perfaz $30,82 \% \%$ do preço de venda praticado pelo atacadista.

No último elo da cadeia de suprimentos, a mercadoria é vendida para o consumidor final por R\$1.000,00. Com isso, o custo tributário foi obtido pelas Equações 5 e 13.

$$
\begin{aligned}
& \mathrm{ICms}_{4}=(1.000 \times 0,18)-(72,00+36,00+36,00)=36,00 \\
& \text { PisCof }_{4}=(1.000 \times 0,0925)-(37,00+18,50+18,5)=18,50
\end{aligned}
$$

Assim, o custo tributário do último elo é de $\mathrm{R} \$ 54,50$. Em toda a cadeia, o custo tributário total foi de $\mathrm{R} \$ 301,07$, representando $30,11 \%$ do preço de venda ao consumidor final.

De forma detalhada, o custo total do ICMS é representado pelo somatório do ICMS recolhido em cada etapa da cadeia de suprimentos, representando, no caso desse exemplo, um montante de $\mathrm{R} \$ 180,00$, que representa $18 \%$ sobre o preço de venda ao consumidor, estando embutido nesse preço. No exemplo, o custo do PIS e da COFINS perfaz um montante de R\$ 92,50, que está embutido no preço de venda, representando 9,25\% sobre ele. O custo do IPI é de $\mathrm{R} \$ 28,57$, o que representa $2,85 \%$ do preço de venda sugerido no exemplo. A redução no percentual do IPI ocorre pelo fato de que esse tributo incide apenas sobre as etapas industriais ou de importação. 
A partir dos custos tributários de cada elo, utilizam-se as Equações 20 e 21 para apurar o custo financeiro dos tributos sobre o consumo:

$$
\begin{aligned}
\text { CustoFin }=\{ & {\left.[72,00+37,00+19,05] \times\left[(1+0,02)^{12}-1\right]\right\} } \\
& +\left\{[36,00+18,50+9,52] \times\left[(1+0,02)^{8}-1\right]\right\} \\
& +\left\{[36,00+18,50] \times\left[(1+0,02)^{4}-1\right]\right\}=34,35+10,99+4,49=49,83 \\
\text { CustoFin }_{\%}= & \frac{49,83}{1.000} \times 100=4,98 \%
\end{aligned}
$$

Somando-se o custo tributário de $\mathrm{R} \$ 301,07$ ao custo financeiro de R $\$ 49,83$, tem-se um valor de $\mathrm{R} \$ 350,90$, que representa $35,09 \%$ do preço de venda ao consumidor estabelecido no presente exemplo. Dessa forma, quanto maior o custo tributário nos elos iniciais e maior o tempo que o produto leva até o consumidor final, mais impactante será o custo financeiro no preço final do produto. Além disso, a não observação correta do custo tributário e, principalmente, do custo financeiro gerado pelos tributos poderá diminuir as margens de lucros esperadas pelas empresas.

Diante desses resultados, é possível inferir que mensuração do custo financeiro decorrente do custo tributário pode auxiliar as empresas ao longo da cadeia produtiva a formatar seus preços de venda e a planejar melhor suas margens de lucro, melhorando sua competitividade. Conhecer o custo tributário e o custo financeiro gerado pelos tributos indiretos pode propiciar à empresa uma vantagem competitiva, por meio de uma gestão tributária mais eficaz, bem como pelo redimensionamento do tempo de distribuição e da agregação de valores e margens no decorrer da cadeia produtiva.

\subsection{Análise de Sensibilidade}

A análise de sensibilidade para verificar alterações percentuais em uma variável de interesse em diferentes cenários projetados pode ser feita por meio de modelos de regressão linear (COYLE; BUXTON; O'BRIEN, 2003; MACHADO; SIMÕES, 2008). No presente, estudo foram simulados 200 cenários distintos de cadeias de suprimentos para um produto fictício, com o objetivo de analisar a sensibilidade do custo financeiro em relação ao preço de venda e ao tempo que o produto leva até chegar ao consumidor em cada etapa desse processo. Os procedimentos para análise de regressão linear foram seguidos conforme explanado por Gujarati (2006).

Com base na demonstração do modelo (Tópico 4), foram gerados números aleatórios normalmente distribuídos para o tempo que o produto passou em cada elo da cadeia, assim como para o valor de transformação na respectiva etapa. A partir desses valores, foi estimado o tempo dos elos até o consumidor e o valor final de venda em cada etapa até o ato da compra. Para que fosse possível estabelecer parâmetros comparativos, o tempo que o consumidor teve acesso ao produto no varejo foi considerado zero, e o valor final de venda foi fixado em 1.000 em todos os cenários.

Com base nas estatísticas descritivas das simulações (Tabela 1), foi possível visualizar um panorama geral dos cenários estimados. A cadeia de suprimentos padrão apresentou 12,04 meses do insumo até o consumo final e variou, para um caso máximo, de 22,2 , e mínimo de 1,64 meses. O tempo médio de um elo para outro foi de quatro meses. Em relação aos valores de venda, foi verificado que, em média, houve uma agregação de valor de aproximadamente

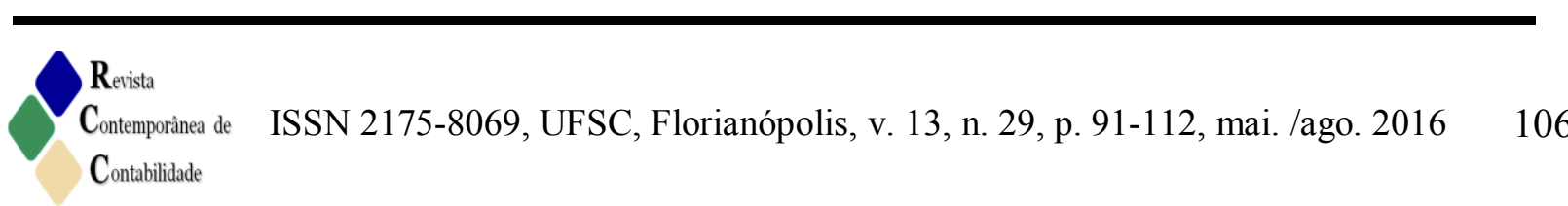


R\$ 200,00 por elo. Esses valores estão condizentes com a demonstração do modelo (Sessão 4).

Tabela 1 - Análise descritiva das variáveis tempo e valor agregado

\begin{tabular}{lllllllll}
\hline & Tempo1 & Tempo2 & Tempo3 & Tempo4 & Valor1 & Valor2 & Valor3 & Valor4 \\
\hline Média & 12,04 & 8,04 & 4,08 & 0,00 & 403,53 & 601,97 & 801,67 & 1000,0 \\
\hline Desv.Pad. & 3,64 & 2,84 & 1,89 & 0,00 & 84,21 & 70,75 & 53,095 & 1000,0 \\
\hline Máximo & 22,20 & 15,32 & 9,20 & 0,00 & 623,76 & 794,68 & 924,82 & 1000,0 \\
\hline Mínimo & 1,64 & 0,87 & 0,06 & 0,00 & 127,35 & 426,78 & 639,35 & 1000,0 \\
\hline
\end{tabular}

Fonte: Elaborado pelos autores.

Deve-se ressaltar que as variáveis Tempo2 e Valor2 foram altamente correlacionadas, superiores a $80 \%$, com as respectivas variáveis explicativas de seus modelos, logo, para evitar a multicolinearidade, estas foram excluídas da análise. Os dois modelos também foram estimados sem intercepto, visto que, caso as variáveis explicativas assumirem o valor de zero, a variável dependente assumirá esse mesmo valor. Os resultados estão dispostos na Tabela 2.

Tabela 2 - Análise de sensibilidade da mensuração dos custos financeiros em uma cadeia de suprimentos

\begin{tabular}{|c|c|c|c|c|c|c|c|}
\hline \multicolumn{4}{|c|}{ Modelo 1} & \multicolumn{4}{|c|}{ Modelo 2} \\
\hline & Coeficiente & Erro padrão & p-valor & & Coeficiente & Erro padrão & p-valor \\
\hline Tempo1 & 0,0034 & 0,00011 & $0,00000 * * *$ & Valor 1 & 0,0000431 & 0,00002 & $0,01110 * *$ \\
\hline Tempo3 & 0,0022 & 0,00028 & $0,00000 * * *$ & Valor3 & 0,0000416 & 0,00001 & $0,00000 * * *$ \\
\hline
\end{tabular}

** Coeficiente significativo ao nível de $95 \%$ de confiança.

***Coeficiente significativo ao nível de $99 \%$ de confiança.

Fonte: Elaborado pelos autores.

A análise de regressão do custo financeiro em função do tempo (Modelo 1) pelo método dos Mínimos Quadrados Ordinários (MQO) apresentou problemas de heterocedasticidade, logo foi realizado o procedimento de sua correção, também conhecido por Mínimos Quadrados Ponderados. O teste de normalidade de Jarque-Bera não rejeita a hipótese nula de que os resíduos são normalmente distribuídos com um p-valor de 0,09 . As variáveis Tempo1 e Tempo3 apresentaram um fator de inflação da variância de 1,42, o que não indicou problema de multicolinearidade. $\mathrm{O} \mathrm{R}^{2}$ obtido foi de $68 \%$ e indicou que o modelo apresentou um alto poder de explicação para o custo financeiro.

$\mathrm{Na}$ regressão do custo financeiro, em função do valor de venda (Modelo2) pelo MQO, a hipótese nula de ausência de heterocedasticidade não foi rejeitada pelo teste de White com p-valor de 0,52. A hipótese nula de normalidade dos resíduos pelo teste de Jarque-Bera não foi rejeitada com um p-valor de 0,06 . Tanto Valor1 quanto Valor3 apresentaram 1,5 de fator de inflação da variância que não ocasionou uma multicolinearidade. O poder explicativo do modelo indicado pelo $\mathrm{R}^{2}$ foi elevado e na magnitude de $90 \%$.

Pela análise de sensibilidade (Tabela 2), foi verificado que quanto maior o tempo do produto até o seu consumo, maior o custo financeiro. Foi verificado que a cada mês adicional no primeiro ou no terceiro elo, o custo financeiro tendeu a se elevar em $0,34 \%$ e $0,22 \%$, respectivamente. Foi constatado também que o valor de venda, na primeira e na terceira etapa da produção, foi diretamente proporcional ao custo financeiro. Notou-se que um acréscimo de $\mathrm{R} \$ 100,00$ na etapa 1 ou na 3 , em média, gerou um aumento de $0,431 \%$ e $0,416 \%$ no custo financeiro, respectivamente. 
Embora o Tempo2 e o Valor2 tenham sido eliminados dos resultados, a análise de sensibilidade demostrou que o custo financeiro foi sendo onerado ao longo das diversas etapas da cadeia de suprimentos, conforme era esperado. Assim, o consumidor final é quem arca com esse custo devido à regressividade do sistema tributário nacional.

\section{Considerações Finais}

O objetivo do presente trabalho foi analisar a sensibilidade do custo financeiro dos tributos indiretos sobre um produto simulado, em relação aos fatores tempo e valor agregado, até o seu consumo final. Para isso, propôs-se uma metodologia para mensurar esse custo financeiro ao longo da cadeia de suprimento a partir de uma série de equações desenvolvidas para calcular o custo do ICMS, do PIS e da COFINS e do IPI, incidentes sobre as operações de cada elo da cadeia. A partir disso, chegou-se a uma equação que, ao ser aplicada, se encontra o valor do custo financeiro que onera, juntamente com os tributos indiretos, o preço de venda dos produtos.

Além disso, realizou-se a simulação para apuração do custo financeiro em uma cadeia de suprimento com cinco entes e quatro elos. A simulação demonstrou que o modelo é aplicável e que, a partir dele, se pode apurar o custo dos tributos sobre o consumo e o custo financeiro que esses tributos geram. Com isso, observou-se que a regressividade da matriz tributária nacional provoca uma oneração nas fases iniciais da cadeia de suprimentos o que, consequentemente, aumenta o preço final dos produtos devido aos tributos nele embutidos. Ademais, o preço final dos produtos também é onerado pelo custo financeiro provocado pela cobrança desses tributos ao longo da cadeia.

Com a finalidade de mensurar a sensibilidade da proposta analítica às alterações de valores e tempo ao longo da cadeia de suprimentos, foi gerada uma análise de sensibilidade, por meio de regressão, sobre 200 cenários distintos formados a partir de valores e tempo aleatórios. Essa análise demonstrou a tese de que quanto mais longa a cadeia produtiva, maior será o custo financeiro provocado pelos tributos indiretos. A regressão demonstrou que há um aumento de $0,34 \%$ e de $0,22 \%$ no custo financeiro para cada mês adicionado, respectivamente, no primeiro e no terceiro elo da cadeia. Além disso, pelo modelo verificouse que um acréscimo de $\mathrm{R} \$ 100,00$ no primeiro e no terceiro provoca um aumento no custo financeiro de $0,431 \%$ e $0,416 \%$, respectivamente, o que demonstra a tese de que a agregação de valores nos elos iniciais da cadeia provoca um aumento no custo financeiro.

Assim, é possível inferir que o modelo proposto pode auxiliar as empresas ao longo da cadeia de suprimentos na gestão tributária, bem como na formação do preço de venda e no planejamento das margens de lucro. Além disso, a correta mensuração do custo tributário e do custo financeiro provocado pelos tributos indiretos pode propiciar às empresas uma vantagem competitiva, por meio do redimensionamento do tempo de distribuição e da agregação de valores e margens no decorrer da cadeia produtiva.

Diante do exposto, conclui-se que o modelo é aplicável para mensurar o custo tributário e o custo financeiro provocado pelos tributos sobre o consumo ao longo da cadeia de suprimento, bem como mensurar o efeito desses custos no preço final de venda dos produtos. Feito isso, defende-se a tese de que o custo financeiro dos tributos sobre o consumo influencia o preço de venda ao longo da cadeia produtiva.

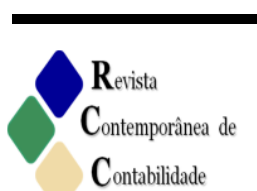


$\mathrm{Na}$ oportunidade, destaca-se, como limitações do trabalho, o fato de que a proposta analítica apresentada se trata de um modelo generalista, que não levou em conta os detalhes e as variações exigidas pela legislação tributária nos vários tipos de operações e de produtos. Além disso, ressalta-se que a validação da proposta foi realizada por meio de dados simulados, uma vez que o objetivo foi o de desenvolver um modelo analítico, e não o de mensurar o custo financeiro em uma cadeia específica.

Para estudos futuros, sugere-se a aplicação da proposta metodológica em um caso real e a melhoria do modelo a partir das exigências legais e das variações nas formas tributárias ao longo da cadeia de suprimentos. Além disso, sugere-se aprimorar o modelo levando em consideração outras variáveis, tais como margens de lucro, regimes tributários e tipos de produtos e aplicá-lo em dados secundários de empresas, com a finalidade de tentar explicar os principais fatores determinantes do custo tributário no custo total das mercadorias.

\section{Referências}

ABRANTES, Luiz Antônio; REIS, Ricardo Pereira; SILVA, Maisa Pereira. The indirect taxation on costs of the coffee production and commercialization. Custos e @gronegócio, v. 5, n. 1, p. 41-60, 2009.

ALM, James; SENNOGA, Edward; SKIDMORE, Mark. Perfect competition, urbanization, and tax incidence in the retail gasoline market. Economic Inquiry, v. 47, n. 1, p. 118-134, 2009.

ARZU AKYUZ, Goknur; ERMAN ERKAN, Turan. Supply chain performance measurement: a literature review. International Journal of Production Research, v. 48, n. 17, p. 5137$5155,2010$.

ASSAF NETO, Alexandre. Matemática Financeira e suas Aplicações. 12. ed. São Paulo: Atlas, 304 p., 2012.

BRASIL. Constituição da República Federativa do Brasil de 1988. Brasília, DF: Senado, 1988.

BRASIL. Lei Complementar n. 87, de 13 de setembro de 1996. Dispõe sobre o imposto dos Estados e do Distrito Federal sobre operações relativas à circulação de mercadorias e sobre prestações de serviços de transporte interestadual e intermunicipal e de comunicação, e dá outras providências. Diário Oficial da República Federativa do Brasil, Brasília, 16 set. 1996; Seção 01, p. 18261.

BALAJI, Kannan; VISWANADHAM, Nukala. A tax integrated approach for global supply chain network planning. IEEE Transactions on Automation Science and Engineering, v. 5 , n. 4, p. 587-596, 2008.

BURGESS, Kevin; SINGH, Prakash J.; KOROGLU, Rana. Supply chain management: a structured literature review and implications for future research. International Journal of Operations \& Production Management, v. 26, n. 7, p. 703-729, 2006. 
CNOSSEN, Sijbren. Mobilizing VAT revenues in African countries. International Tax and Public Finance, v. 22, n. 6, p. 1077-1108, 2015.

COYLE, Douglas; BUXTON, Martin J.; O'BRIEN, Bernie J. Measures of importance for economic analysis based on decision modeling. Journal of Clinical Epidemiology, v. 56, n. 10, p. 989-997, 2003.

DALLEMOLE, Dilamar; DE OLIVEIRA FALLEIROS, Ricardo; DE MELO FARIA, Alexandre Magno. Estudo Locacional da Cotonicultura de Mato Grosso com Base na Arrecadação de ICMS. Desenvolvimento em Questão, v. 11, n. 22, p. 95-116, 2013.

DEATON, Angus. Optimal Taxes and Structure of Preferences. Econometrica, v. 49, n. 5, p. 1245-1260, 1981.

DYRENG, Scott D.; LINDSEY, Bradley P.; MARKLE. Kevin S.; SHACKELFORD, Douglas A. The effect of tax and nontax country characteristics on the global equity supply chains of U.S. multinationals. Journal of Accounting and Economics. v. 52. p. 182-202, 2015.

ERNEST \& YOUNG. Managing indirect taxes in the supply chain Supporting growth and reducing cost and risk. London: EYGM Limited. 2012.

FABBE-COSTES, Nathalie; JAHRE, Marianne. Supply chain integration and performance: a review of the evidence. The International Journal of Logistics Management, v. 19, n. 2, p. 130-154, 2008.

FENG, Cheng-Min; WU, Pei-Ju. A tax savings model for the emerging global manufacturing network. International Journal of Production Economics, v. 122, n. 2, p. 534-546, 2009.

FERNANDES, Fernando Alberto Dutra; TEIXEIRA, Arilton; BAPTISTA, Ézio C. S. COFINS: Um Estudo Empírico dos Efeitos da Alteração de Incidência sobre o Lucro de Empresas com Ações Negociadas na Bovespa e seu Impacto na Arrecadação Tributária Federal. Revista Brasileira de Gestão de Negócios, v. 12, n. 35, p. 171-190, 2010.

FREITAS, J. B.; REVILLION, J. P.; BELARMINO, L. C. Análise da Competitividade da Cadeia Produtiva do Leite em Pó Integral. RAC Revista de Administração Contemporânea (Online), v. 19, p. 750-771, 2015.

GASSEN, Valcir; D'ARAÚJO, Pedro Júlio Sales; PAULINO, Sandra Regina da F. Tributação sobre Consumo: o esforço em onerar mais quem ganha menos. Sequência: Estudos

Jurídicos e Políticos, v. 34, n. 66, p. 213-234, 2013.

GLOVER, J. L. et al. An Institutional Theory perspective on sustainable practices across the dairy supply chain. International Journal of Production Economics, v. 152, p. 102-111, 2014. 
GUJARATI, Damodar. Econometria básica. 4. ed. Rio de Janeiro: Elsevier, 812 p., 2006.

INSTITUTO BRASILEIRO DE PLANEJAMENTO E TRIBUTAÇÃO. Evolução da Carga Tributária Brasileira. Maio de 2015. Disponível em:

https://www.ibpt.com.br/img/uploads/novelty/estudo/2142/05EvolucaoDaCargaTributariaBra sileira.pdf. Acesso em junho de 2016.

KEEN, Michael; LOCKWOOD, Ben. The value added tax: Its causes and consequences. Journal of Development Economics, v. 92, n. 2, p. 138-151, 2010.

KOPCZUK, W. et al. Does tax-collection invariance hold? evasion and the pass-through of state diesel taxes. American Economic Journal: Economic Policy, v. 8, n. 2, p. 251-86, 2016.

MACHADO, Flávia Mori Sarti; SIMOES, Arlete Naresse. Análise custo-efetividade e índice de qualidade da refeição aplicados à Estratégia Global da OMS. Revista de Saúde Pública, v. 42, n. 1, p. 64-72, 2008.

MARQUEZINI, Simone Vilela. Sistema tributário nacional: os descaminhos das últimas reformas. Revista Ibero-Americana de Estratégia, v. 4, n. 1, p. 35-44, 2007.

MARION, Justin; MUEHLEGGER, Erich. Fuel tax incidence and supply conditions. Journal of Public Economics, v. 95, n. 9, p. 1202-1212, 2011.

MENTZER, John T. et al. Defining supply chain management. Journal of Business Logistics, v. 22, n. 2, p. 1-25, 2001.

MINAS GERAIS. Decreto 43.080, de 13 de dezembro de 2002. Aprova o regulamento do imposto sobre operações relativas à circulação de mercadorias e sobre prestação de serviços de transporte interestadual e intermunicipal e de comunicação (RICMS), 2002.

NETO, A. M. O efeito da inflação sobre a arrecadação do ICMS. Indicadores Econômicos FEE, v. 18, n. 3, p. 181-193, 1990.

PAES, Nelson Leitão. O custo da ineficiência da tributação indireta brasileira. Revista Brasileira de Economia de Empresas, v. 12, n. 2, 2013.

PÊGAS, Paulo Henrique. Manual de Contabilidade Tributária. 4. ed. Rio de Janeiro: Freitas Bastos, 2006.

RECEITA FEDERAL. Carga Tributária no Brasil 2014: análise por tributos e bases de incidência. Outubro de 2015. Disponível em:

http://idg.receita.fazenda.gov.br/dados/receitadata/estudos-e-tributarios-e-aduaneiros/estudose-estatisticas/carga-tributaria-no-brasil/29-10-2015-carga-tributaria-2014. Acesso em junho de 2016. 
REGAZZINI, Leonardo Coviello; BACHA, Carlos José Caetano. A tributação no setor sucroenergético do estado de São Paulo: anos de 2000 e 2008. Revista de Economia e Sociologia Rural, Brasília, v. 50, n. 4, p. 801-818, 2012.

ROSS, Stephen A.; WESTERFIELD, Randolph W.; JAFFE, Jeffrey; LAMB, Roberto.

Administração Financeira. 10. ed. Porto Alegre: AMGH, 1072 p., 2015.

SILVA, Denize M.; PAYERAS, José Adrian P. Carga Tributária Indireta sobre os Alimentos na Região Sul do Brasil. Economia \& Região, v. 1, n. 2, p. 45 - 60, 2013.

TRABANDT, Mathias; UHLIG, Haraldt. The Laffer Curve Revisited. Journal of Monetary Economics, v. 58, p 305-327, 2011.

WEBBER, Stuart. The Tax-Efficient Supply Chain: Considerations for Multinationals. Tax Notes International, v. 61, n. 2, p. 149-168, 2011.

ZHANG, Yan; HUANG, J. H. Cost-based pricing model with value-added tax and corporate income tax for a supply chain network. Applied Mathematical Modelling, v. 38, p. 168-180, 2014. 